Research Paper

\title{
MicroRNA-148b enhances the radiosensitivity of B-cell lymphoma cells by targeting Bcl-w to promote apoptosis
}

\author{
Si-hong Liu1, 6, \#, Pei-pei Wang2, 6, \#, Cun-te Chen³, 6, Dan Li2,6, Qiong-yao Liu'2, 6, Lin Lv2, 6, Xia Liu'2, 6, Li-na \\ Wang2, 6, Bao-xiu Li2, 6, Cheng-yin Weng2, 6, Xi-sheng Fang2, 6, Xiao-fei Cao 2, 6, Hai-bo Mao 2, 6, Xiao-jun \\ Chen ${ }^{2}$ 6, Shao-li Luo ${ }^{4}, 6$, Shu-xiang Zheng5, 6, Guo-long Liu², 6, $₫$, Yong Wu'2, 6, \\ 1. Department of Orthopaedics, Guangzhou First People's Hospital, School of Medicine, South China University of Technology, Guangzhou, Guangdong, \\ China \\ 2. Department of Oncology, Guangzhou First People's Hospital, School of Medicine, South China University of Technology, Guangzhou, Guangdong, China \\ 3. Department of Hematology, Guangzhou First People's Hospital, School of Medicine, South China University of Technology, Guangzhou, Guangdong, \\ China \\ 4. Department of Gerontology, Guangzhou First People's Hospital, School of Medicine, South China University of Technology, Guangzhou, Guangdong, \\ China \\ 5. Department of Obstetrics, Guangzhou First People's Hospital, School of Medicine, South China University of Technology, Guangzhou, Guangdong, China \\ 6. Guangzhou First People's Hospital, Guangzhou Medical University, Guangzhou, Guangdong, China
}

\#These authors contributed equally to this work.

$\square$ Corresponding authors: Yong Wu, Department of Oncology, Guangzhou First People's Hospital, School of Medicine, South China University of Technology; Guangzhou First People's Hospital, Guangzhou Medical University, 1 Panfu Road, Guangzhou, Guangdong 510180, China. Tel: +86(20)81045125; Email: eywuyong@scut.edu.cn or Guo-long Liu, Department of Oncology, Guangzhou First People's Hospital, School of Medicine,South China University of Technology; Guangzhou First People's Hospital, Guangzhou Medical University, 1 Panfu Road, Guangzhou, Guangdong 510180, China. Tel: +86(20)81045125; Email: eyglliu@scut.edu.cn

(c) The author(s). This is an open access article distributed under the terms of the Creative Commons Attribution License (https://creativecommons.org/licenses/by/4.0/). See http://ivyspring.com/terms for full terms and conditions.

Received: 2019.10.22; Accepted: 2019.12.26; Published: 2020.01.23

\begin{abstract}
Lymphoma is a malignant disease of the hematopoietic system that typically affects $B$ cells. The up-regulation of miR-148b is associated with radiosensitization in B-cell lymphoma $(B C L)$. This study aimed to explore the role of miR-148b in regulating the radiosensitivity of $B C L$ cells and to investigate the underlying mechanism. miR-148b directly targeted $\mathrm{Bcl}-\mathrm{w}$, decreased the cell viability and colony formation, while promoted apoptosis, in irradiated BCL cells. These changes were accompanied by decreased mitochondrial membrane potential, release of cytochrome $\mathrm{C}$, increased levels of the cleaved caspase 9 and caspase 3, and increased expression of other proteins related to the mitochondrial apoptosis pathway. These effects of miR-148b were effectively inhibited by Bcl-w. In addition, miR-148b inhibited the growth of tumors in nude mice implanted with xenografts of irradiated Raji cells. In patients with $B C L$, levels of miR-148b were downregulated, while levels of $\mathrm{Bcl}-\mathrm{w}$ were upregulated; a significant negative correlation between levels of miR-148b and $\mathrm{Bcl}-\mathrm{w}$ was confirmed. Taken together, these experiments showed that miR-148b promoted radiation-induced apoptosis in BCL cells by targeting anti-apoptotic Bcl-w. miR-148b might be used as a marker to predict the radiosensitivity of BCL.
\end{abstract}

Key words: miR-148b; radiosensitivity; B-cell lymphoma; Bcl-w; apoptosis

\section{Introduction}

Abnormalities in apoptotic signaling contribute to tumorigenesis and tumor development; they also play a key role in radiosensitivity. Altered expression of apoptosis-related proteins such as surviving [1], BIRC7 [2], Mcl-1 [3], and Bcl-2 [4] has been found in malignant lymphoma. Anti-apoptotic proteins in the Bcl-2 family, such as Bcl-2 [5, 6] and Bcl-xl $[7,8]$, are key to cell survival and often overexpressed in malignant tumors, leading to increased cancer cell survival. Bcl-w is a member of the Bcl-2 family, which acts directly on pro-apoptotic proteins to inhibit apoptosis [9-11], and play a key role in the development and progression of various malignancies, and is involved in radiation-induced cell death [12]. Upregulation of Bcl-w promotes tumorigenesis while downregulation of Bcl-w 
promotes cancer cell apoptosis [13, 14]. Bcl-w may act through MYC to regulate the transcription of specific miRNA in order to increase B cell apoptosis [13]. Conversely, the use of miRNA to suppress the expression of $\mathrm{Bcl}-\mathrm{w}$ decreases the proliferation and invasion of clear-cell renal cell carcinoma cells [15]. Cyramza (ramucirumab) is a human VEGF receptor-2 antagonist that inhibits angiogenesis and growth. The drug was approved for the treatment of multiple malignancies in 2014. Cyramza may act on Bcl-w to induce the apoptosis of HCC4006 cells [16]. These findings support a role for Bcl-w in B-cell lymphoma (BCL).

MiRNAs are critical to cell growth, development, proliferation, differentiation, and death [17]. Growing evidence has demonstrated that miRNAs are involved in the regulation of tumor radiosensitivity [18-27]. It has previously been reported that miR-148b acts as a tumor suppressor in the context of lung cancer [28], cervical cancer [29], and gastric cancer [30]. In addition, miR-148b is downregulated in breast cancer [31], colorectal cancer [32], and hepatocellular carcinoma [2]. We have reported that radiation therapy upregulates miR-148b, thus enhancing the radiosensitivity of $\mathrm{BCL}$ cells by promoting radiation-induced apoptosis [33].

Overexpression of miR-148a in a colorectal cancer cell line led to decreased expression of Bcl-2 and Bcl-XL [34]. Bcl-w protein is an important anti-apoptotic protein in the Bcl-2 family, which regulates the mitochondrial apoptotic pathway [35]. Bcl-w knockout animals showed significantly more apoptosis than wild-type counterparts in small intestine as well as mid-colon after irradiation [36]. Bioinformatics analysis and the results of preliminary experiments indicate that Bcl- $\mathrm{w}$ may be the target of $\mathrm{miR}-148 \mathrm{~b}$ [35]. However, it is not clear if miR-148b really acts on Bcl-w and plays a role in the radiosensitivity of $\mathrm{BCL}$.

In this study, we sought to confirm Bcl-w as the target gene of miR-148b in BCL cells and to investigate the role of miR-148b and Bcl-w in the regulation of radiosensitivity and mitochondrial apoptosis in BCL cells.

\section{Materials and Methods}

\section{Patients}

A total of 51 patients diagnosed with BCL based on World Health Organization (WHO) classification criteria were enrolled at our hospital during the period from February 2017 to March 2019. Peripheral blood specimens from 21 newly diagnosed patients were collected before treatment. Peripheral blood specimens from 18 healthy volunteers were included as control. Lymphatic tissue specimens from 30 newly diagnosed patients were collected before treatment. Lymphatic tissue specimens from 18 healthy volunteers were included as control (Table 1). All subjects gave their informed consent for inclusion before they participated in the study. The study was conducted in accordance with the Declaration of Helsinki, and the protocol was approved by the Ethics Committee of Guangzhou First People's Hospital (Project identification code: K-2017-133-01).

Table 1. Clinical information of $B C L$ and healthy volunteers

\begin{tabular}{llll}
\hline Variables & Peripheral blood & Lymphatic tissue & $p$ value \\
\hline $\begin{array}{l}\text { Age (mean } \pm \text { SD, years) } \\
\text { Gender, n (\%) }\end{array}$ & $57 \pm 18$ & $59 \pm 15$ & $0.668^{*}$ \\
Male & $12(57.1)$ & $21(70.0)$ & \\
Female & $9(42.9)$ & $9(30.0)$ & $0.127^{\#}$ \\
Histology, n (\%) & & & \\
Diffuse large B-cell & $9(42.9)$ & $13(43.3)$ & \\
lymphoma & & & \\
Marginal zone lymphoma & $6(28.6)$ & $3(10.0)$ & \\
Follicular lymphoma & $5(23.8)$ & $5(16.7)$ & \\
Mantle cell lymphoma & $1(4.7)$ & $4(13.3)$ & \\
Burkitt lymphoma & $0(0.0)$ & $5(16.7)$ & \\
Stage, n (\%) & & & \\
I & $1(4.8)$ & $4(13.3)$ & \\
II & $2(9.5)$ & $6(20.0)$ & \\
III & $11(52.4)$ & $13(43.3)$ & \\
IV & $7(33.3)$ & $7(23.4)$ & \\
Healthy volunteers, $\mathrm{n}$ & 18 & 20 & \\
\hline
\end{tabular}

Note: *Independent-sample Student's t-test; \# Chi-square test.

\section{Isolation of mononuclear cells}

A peripheral blood sample was added to the surface of $5 \mathrm{ml}$ Ficoll $(1.077 \mathrm{~g} / \mathrm{mL}$; GE Healthcare Life Sciences), then centrifuged at $670 \times g$ in a centrifuge at $25^{\circ} \mathrm{C}$ for 25 minutes. After centrifugation, the liquid was divided into three layers. The narrow white turbid layer between the upper and middle layers, which consisted mainly of mononuclear cells (MNCs), was pipetted into another centrifuge tube, and MNCs were washed twice with PBS. Finally, 5-10 × $10^{6}$ MNCs were stored in TRIzol reagent (Invitrogen).

\section{Cell culture}

Raji and SU-DHL-10 human BCL cell lines were obtained from ATCC and cultured in RPMI-1640 medium (Hyclone, USA) containing 10\% (v/v) fetal bovine serum (Gibco, USA), $100 \mathrm{U} / \mathrm{ml}$ penicillin, and $100 \mu \mathrm{g} / \mathrm{ml}$ streptomycin (Gibco, USA) in an incubator containing $5 \% \mathrm{CO}_{2}$ at $37^{\circ} \mathrm{C}$. All experiments were performed with exponentially growing cells. HEK-293T cells were obtained from the Chinese Academy of Sciences and cultured in Dulbecco modified Eagle medium containing $10 \%(\mathrm{v} / \mathrm{v})$ fetal bovine serum (Gibco, USA), $100 \mathrm{mg} / \mathrm{mL}$ penicillin, and $100 \mathrm{U} / \mathrm{mL}$ streptomycin (Gibco, USA) in an incubator containing $5 \% \mathrm{CO}_{2}$ at $37^{\circ} \mathrm{C}$. 


\section{Irradiation}

External beam radiation was performed by using an Elekta Precise Linear Accelerator (Elekta Oncology Systems, UK), equipped with a 6-MV photon beam. A field size of $40 \times 40 \mathrm{~cm}$ was used. Petri dishes were placed in a $1.5-\mathrm{cm}$ superflab bolus, at a distance of 100 $\mathrm{cm}$ from the source. The calculated monitoring unit (MU) delivered the dose to a depth of $d_{\max }$ at $2.5 \mathrm{~Gy} / \mathrm{min}$. Cells were removed from the incubator and transferred to the site for radiation. The radiation dose of 2 Gy or 4 Gy was verified and confirmed after calibration with the accelerator's dosimeter. The blank or vector-transfected cells after irradiation were used as controls.

Table 2. Sequences of the primers

\begin{tabular}{ll}
\hline Target & Sequence 5' $^{\prime}$ 3' $^{\prime}$ \\
\hline Bcl-w wt (F) & CCGCTCGAGAAGCCAGGGCCAGGTGGG \\
Bcl-w wt (R) & ATAAGAATGCGGCGCTCAGTCCTTCTCATTAAACTTCTGGG \\
Bcl-w mut(F) & AACCCTGCCTGTGTCCTGACGTGACTTCACCTTAGCTAGAC \\
& CATGG \\
Bcl-w & CCATGGTCTAGCTAAGGTGAAGTCACGTCAGGACCACAGGC \\
mut(R) & AGGGTT \\
miR-148b (F) & CCGCTCGAGTCATTTGCAGCAGCCTAGTTGC \\
miR-148b (R) & CGCGGATCCACTGAGAAATGGGCTTCCAGGAC \\
miR-148b & CGCGGATCCCCGGACAAAGTTCTTCATGCAC \\
inhibitor (F) & \\
miR-148b & CCGGAATTCCCGGCAGTGCATGAAGAACTT \\
inhibitor (R) & \\
ORF of Bcl-w & CGGGGTACCGCCACCATGGCGACCCCAGCCTCGGCCCC \\
(F) & \\
ORF of Bcl-w & CCGCTCGAGTCACTTGCTAGCAAAAAAGGCCCCTAC \\
(R) & \\
has-miR-148 & GTCGTATCCAGTGCAGGGTCCGAGGTATTCGCACTGGATACG \\
b-3p- RT & ACCACAAAGTT \\
has-mir-148b & ATGGTTCGTGGGTCAGTGCATCACAGAACTTT \\
(F) & \\
has-mir-148b & GTGCAGGGTCCGAGGT \\
(R) & \\
U6 (F) & CTCGCTTCGGCAGCACA \\
U6 (R) & AACGCTTCACGAATTTGCGT \\
U6-RT & GTCGTATCCAGTGCAGGGTCCAGGTATTCGCACTGGATACG \\
Bcl-w (F) & ACCAAATATGGAAC \\
Bcl-w (R) & CCCACCCAGGTCTCCGATG \\
$\beta$-actin (F) & CATGTACGTTGCTATCCAGGC \\
$\beta$-actin (R) & CTCCTTAATGTCACGCACGAT \\
\hline &
\end{tabular}

\section{Luciferase reporter assay}

The wild type 3'UTR sequence of Bcl-w (wt 3 'UTR), which contains the putative miR-148b binding site, was amplified by PCR using the Bcl-w wt primer pair (Table 2). A mutated 3' UTR (mut 3' UTR) of Bcl-w was generated through site-directed mutagenesis with Bcl-w mut primer pair (Table 2) using a Quik-Change Site-Directed Mutagenesis Kit (Stratagene, USA). Both Bcl-w wt 3' UTR and Bcl-w mut 3' UTR were fused with the luciferase reporter gene in the psiCHECK-2 vector (Promega). Raji cells and SU-DHL-10 cells were divided into four groups. One group was co-transfected with Wt 3'UTR vectors, control vectors of psiCHECK-2 (Promega, USA) encoding Renilla luciferase and miR-148b mimic; one group was co-transfected with Wt 3'UTR vectors, control vectors of psiCHECK-2 encoding Renilla luciferase and miR-control; one group was co-transfected with mut $3^{\prime}$ UTR vectors, control vectors of psiCHECK-2, and miR-control; and the fourth group was co-transfected with mut $3^{\prime} \mathrm{UTR}$ vectors, and a control vector encoding Renilla luciferase, control vectors of psiCHECK-2 (Promega, USA) and miR-control, with Lipofectamine 2000 (Invitrogen). After 48h, levels of luciferase activity were detected using the Dual-Luciferase Reporter Assay System (Promega) and normalized with the Renilla values. Values are presented as the ratio of firefly/Renilla values.

\section{Construction of miR-148b mimic and inhibitor lentivirus vectors}

A fragment encoding the miR-148b sequence was amplified from human genomic DNA by PCR, then cloned into the BamHI/XhoI sites of pLVX-IRES-Neo vector to make lentivirus vector pLVX-IRES-Neo-miR-148b (miR-148b mimic). A fragment encoding the miR-148b inhibitor sequence was amplified by PCR, then cloned into the BamHI/EcoRI sites of pLVX-shRNA2 vector to create miR-148b inhibitor.

\section{Lentivirus production and infection}

First, $5 \times 10^{6} 239 \mathrm{~T}$ cells were cultured overnight in a $100-\mathrm{mm}$ plastic petri dish. Second, 293T cells were transfected with miR-148b mimic or inhibitor lentivirus using pLVX-IRES-Neo-miR-148b or pLVX-shRNA2+miR-148b-inhibitor, pHelper 1.0, and pHelper 2.0 in combination with Lipofectamine 2000 (Invitrogen). After 24 hours, the aforementioned medium was collected, centrifuged at 3,000 rpm for 10 minutes at $4^{\circ} \mathrm{C}$, then filtered using a $0.45-\mathrm{mm}$ filter and the filtrate containing the lentivirus was collected for infection. Then $80 \%$ to $90 \%$ confluent Raji cells and SU-DHL-10 cells were infected with miR-148b mimic or inhibitor in the presence of $10 \mathrm{mg} / \mathrm{mL}$ hexadimethrine bromide (Sigma-Aldrich, St. Louis, MO, USA). After 24 hours, a fluorescence activated cell sorter (Becton Dickinson, Mountain View, CA) was used to measure the expression of green fluorescent protein (GFP), as an index for infection efficiency.

\section{Cell transfection}

The open reading frame (ORF) of Bcl-w was amplified and cloned into pCDNA3.1. Bcl-w small interfering RNA (siRNA) was obtained from Sigma (USA). Raji cells and SU-DHL-10 cells were transfected with Bcl-w expression vector, empty 
plasmid, or Bcl-w siRNA with Lipofectamine 2000 (Invitrogen).

\section{Quantitative real-time PCR analysis}

Expression levels of miR-148b were determined using the miRNA-specific assay kit (Takara, China), and U6 was used as an internal control. Expression levels of Bcl-w were detected using SYBR Premix Ex Taq II (Takara, China), with $\beta$-actin as an internal control. Quantitative real-time PCR (qRT-PCR) were performed on an ABI PRISM ${ }^{\circledR} 7500$ Sequence Detection System. The signals were normalized to the internal control and expressed as $2-\Delta \Delta \mathrm{Ct}$.

\section{Immunohistochemistry and scoring}

Pathological lymph tissue specimens from 30 newly diagnosed BCL patients were paraffin-embedded and cut into $2 \mu \mathrm{m}$ sections. Immunostaining was performed as previously described [37]. Briefly, slides were deparaffinized, rehydrated in a series of degrading ethanol solutions and boiled in EDTA (1 mM, pH 8.0). After the endogenous peroxidase was quenched with $0.3 \%$ $\mathrm{H}_{2} \mathrm{O}_{2}$, slides were incubated with the primary antibody of mouse anti-human Bcl-w (Abcam; 1:200) overnight. After incubation with the HRP-conjugated secondary antibody (DAKO EnVision ${ }^{\mathrm{TM}}$ Detection $\mathrm{Kit})$, the signal was visualized using the A solution in the DAKO kit. Sections were then counterstained with hematoxylin. The number of positively stained cells and the staining intensity of 5 randomly selected fields of view were manually counted at $400 x$ high-power magnification (cells/HPF). The score was then determined by calculating the average number of positively stained cells per HPF.

\section{Histological analysis of TUNEL staining}

Pathological lymphatic tissue from 30 newly diagnosed BCL patients was paraffin-embedded and cut into $2 \mu \mathrm{m}$ sections. The slides were deparaffinized, rehydrated in a series of degrading ethanol solutions and then rinsed with $0.1 \%$ Triton X-100 for cell penetration. Apoptotic lymph tissue cells were detected by terminal deoxynucleotidyl transferase-mediated dUTP nick-end labeling (TUNEL) using the TransDetectIn Situ Fluorescein TUNEL Cell Apoptosis Detection Kit (Transgen Biotech, China) [38]. The apoptotic index was determined by TUNEL assay as the percentage of apoptotic events per lymphocyte population in five random fields at 400x high-power magnification (cells/HPF).

\section{Cell viability assay}

Cells were seeded at a density of $1 \times 10^{4}$ cells/well into 96-well plates. After irradiation, cells were cultured in a $5 \% \mathrm{CO}_{2}$ chamber at $37^{\circ} \mathrm{C}$. Viable cells were evaluated using the CCK-8 Assay kit (Beyotime, China) according to the manufacturer's instructions over four consecutive days. CCK-8 was added to the 96-well plates, which were incubated at $37^{\circ} \mathrm{C}$ for 4 hours. The optical density (OD) value of each well was read at a wavelength of $450 \mathrm{~nm}$ using a microplate reader (multiscan MK3, Thermo Fisher Scientific).

\section{Clonogenic assay}

Cells were seeded at a density of 100 cells/ $300 \mu 1$ complete medium and Matrigel (BD Biosciences, USA) into each well of 96-well plates. They were incubated in a chamber containing $5 \% \mathrm{CO}_{2}$ at $37^{\circ} \mathrm{C}$, and then stained with Crystal Violet on Day 8. Colonies were counted with the AID iSpot Reader System.

\section{Annexin V-propidium iodide apoptosis assay}

Approximately $5 \times 10^{5}$ cells were incubated with Alexa Fluor 488-conjugated annexin $\mathrm{V}$ and propidium iodide (PI; Keygen Biotech, China). Apoptotic cells were detected using a FACSCalibur flow cytometer (BD Biosciences, USA) with annexin V+/ PI+ cells labeled as necrotic cells and annexin V+/ PI- cells labeled as apoptotic cells.

\section{Mitochondrial membrane permeability}

Mitochondrial membrane potential (MMP) was assessed using fluorescent probe JC-1 (Life Technologies). Cells seeded in 6-well plates were treated with JC-1 (1 mL per well) at a concentration of $10 \mathrm{ug} / \mathrm{mL}$ for 20 minutes at $37{ }^{\circ} \mathrm{C}$. Fluorescence intensity was detected by a FACSCalibur flow cytometer (BD Biosciences, USA) immediately after washing with serum-free medium. For JC-1 green, Ex $=514 \mathrm{~nm}$ and $\mathrm{Em}=529 \mathrm{~nm}$; for JC-1 red, Ex = $585 \mathrm{~nm}$ and $\mathrm{Em}=590 \mathrm{~nm}$.

\section{Immunofluorescence analysis}

Cytochrome $\mathrm{C}$ was examined by immunostaining with cytochrome $\mathrm{C}$ antibody. Briefly, cells were fixed in $4 \%$ paraformaldehyde and incubated overnight with rabbit anti-cytochrome $\mathrm{C}$ antibody (Abcam; 1:100), then incubated with Alexa Fluor 488-labeled goat anti-rabbit IgG antibody (Life Technologies; 1:200) for 1 hour. Nuclei were stained with DAPI. Images were observed under a laser scanning confocal microscope (Zeiss, Germany).

\section{Western blot analysis}

Protein lysates were separated by SDS-PAGE in a $10 \%$ polyacrimide gel, then transferred to a polyvinylidene difluoride membrane (Millipore, USA). Membranes were incubated with antibody 
against human Bcl-w (Abcam; 1:200), Apaf-1 (Abcam; 1:500), cleaved Caspase-9 (Novus Bio; 1:1,000), cleaved Caspase-3 (CST; 1:1,000), Bax (Abcam; 1:2,000); or GAPDH (KangChen Bio-tech Inc., China). Peroxidase-conjugated goat anti-mouse $\operatorname{IgG}(\mathrm{H}+\mathrm{L})$ (Southern Biotech) was used as the secondary antibody. The intensity of staining was visualized using an X-ray image film processor (Kodak, Japan).

\section{Tumorigenicity}

Male BALB/c nude mice were obtained from the Laboratory Animals Center of Sun Yat-Sen University. Mice were housed under specific pathogen-free conditions in the animal facilities of South China University of Technology. Mice at the age of 6 to 8 weeks were randomly divided into four groups, each of which included 3 mice. Irradiated Raji cells $\left(1 \times 10^{7}\right.$ in $0.2 \mathrm{ml}$ of PBS/mouse $)$ were subcutaneously inoculated into the right flank of each nude mouse included in the study. Tumor volume was calculated using the following formula: $\left(\mathrm{L} \times \mathrm{W}^{2}\right) / 2$, with length $(\mathrm{L})$ and width $(\mathrm{W})$ measured every 3 days. Forty-seven days after implantation the last measurement of tumor volume was performed, and mice were euthanized by inhalation of carbon dioxide followed by cervical dislocation. All animal protocols were approved by the ethics committee at South China University of Technology.

\section{Statistical analysis}

Each experiment was repeated at least 3 times. The difference in quantitative data between the two groups was compared using independent-sample Student 's t-test and Mann-Whitney rank-sum test, as appropriate (Table 1). Differences between multiple groups of quantitative data was performed using one-way ANOVA and Fisher 's exact test, as appropriate. The qualitative data was compared by using Chi-square test. All statistical analyses were conducted using SigmaStat 3.5 (Systat Software, San Jose, CA, USA). $P<0.05$ was considered statistically significant.

\section{Results}

\section{Bcl-w is a target of miR-148b in BCL cells}

The potential targets of miR-148b in BCL cells were screened using the TargetScan bioinformatics prediction algorithm. Among the genes predicted to be targets of miR-148b, Bcl-w is an important anti-apoptotic protein and related to radiosensitivity. The wt 3'UTR or mut 3'UTR of Bcl-w was inserted into a reporter plasmid downstream of the luciferase gene (Figure 1A). These plasmids, miR-148b mimic, or inhibitor, were transiently co-transfected into Raji cells and SU-DHL-10 cells with the Renilla luciferase vector (pRL-TK). Dual-luciferase reporter assay indicated that miR-148b mimic or inhibitor altered the luciferase activity in the cells transfected with the plasmids containing the wt $3^{\prime}$ UTR and the luciferase gene but not the negative control (Figure 1B, lanes 2 and 3; $p$ <.05). Treatment with miR-148b mimic or inhibitor had no effect on the luciferase activity in the cells transfected with the plasmids containing of the mut $3^{\prime}$ UTR and the luciferase gene (Figure 1C, lanes 2 and $3 ; p>0.05)$. miR-148b mimic significantly decreased the levels of Bcl-w mRNA (Figure 1D, $p<$ 0.01 ) and protein (Figure 1E) in the cells transfected with miR-148b mimic. These results suggest that Bcl-w is a direct target of miR-148b in BCL cells.

\section{miR-148b influences the viability and colony formation of BCL cells through targeting Bcl-w}

To investigate whether miR-148b influences the growth of $\mathrm{BCL}$ after ionizing radiation through $\mathrm{Bcl}-\mathrm{w}$, we investigated the effect of Bcl-w on cell viability and colony formation after ionizing radiation treatment in cells expressing various levels of miR-148b. It was found that miR-148b mimics decreased cell viability (Figure 2A-B, $p<0.001$ ) and colony formation (Figure 3A-B, $p<0.05$ ), while miR-148b inhibitor promoted cell viability (Figure $2 \mathrm{~A}-\mathrm{B}, p<0.05$ ) and colony formation (Figure $3 \mathrm{~A}-\mathrm{B}, p<$ 0.001 ), in irradiated BCL cells. Moreover, these effects of miR-148b on cell viability and colony formation were reversed by overexpression or knockdown of Bcl-w (Figure 2-3, $p<0.05$ ). These results suggest that miR-148b targets Bcl-w to inhibit the viability and colony formation of BCL cells after ionizing radiation.

\section{miR-148b reverses $\mathrm{Bcl}-\mathrm{w}-\mathrm{mediated}$ inhibition} of mitochondrial apoptosis in BCL cells

The effect of miR148b on apoptosis was examined in BCL cells with flow cytometry. It was found that the miR-148b mimic promoted apoptosis (Figure 4A-B, $p<0.001$ ), while the miR-148b inhibitor inhibited apoptosis (Figure 4A-B, $p<0.05$ ). It was also found that the effect of the miR-148b mimic or inhibitor could be reversed by overexpression or knockdown of Bcl-w, respectively (Figure 4A-B, $p<$ 0.001). miR148b mimic decreased mitochondrial membrane potential (Figure 5A, $p<0.05$ ) and increased the release of cytochrome $C$ (Figure 5B) in Raji cells. Treatment with miR-148b inhibitor had the opposite effect (Figure 5A-B). Western blot analysis showed that treatment with miR-148b mimic activated the expression of mitochondrial apoptosis-related proteins; however, this effect was reversed by the overexpression of Bcl-w. In contrast, miR-148b inhibitor inhibited the expression of mitochondrial apoptosis-related proteins; this effect 
was reversed by Bcl-w knockdown (Figure 5C, $p<$ $0.05)$. Overall, these results suggest that miR-148b targets Bcl-w to reverse the inhibition of mitochondrial apoptosis in BCL cells.

\section{miR-148b inhibits tumor growth in mice}

Either irradiated Raji cells or irradiated Raji cells transfected with negative control siRNA (NC), miR-148b mimic, or miR-148b inhibitor were subcutaneously inoculated into the right abdomens of nude mice. The size of the tumors was measured, and a tumor growth curve was established. It was found that tumors generated from the cells transfected with the miR-148b mimic grew significantly $(p=0.021)$ slower than the tumors generated from the cells transfected with the negative control siRNA (Figure 6). Tumors generated from the cells transfected with miR-148b inhibitor grew significantly $(\mathrm{p}<0.001)$ faster than the tumors generated from the negative control cells (Figure 6).
A

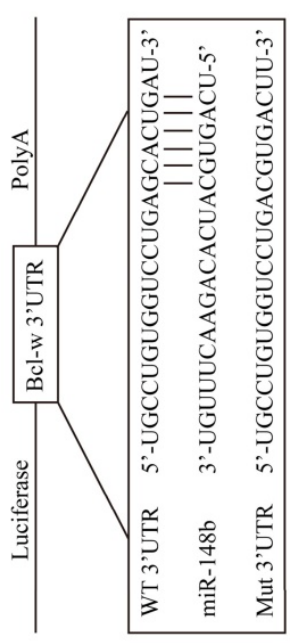

B

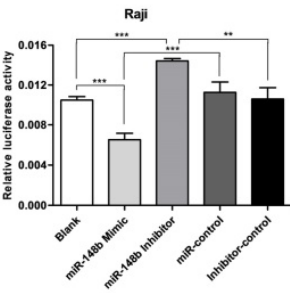

D

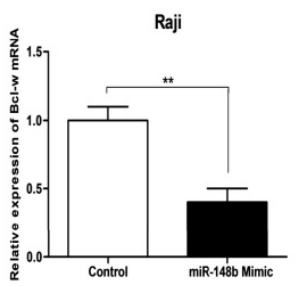

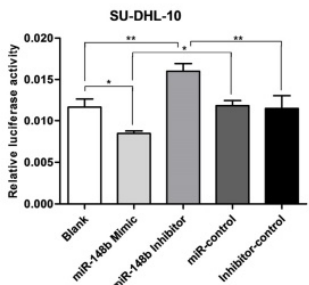

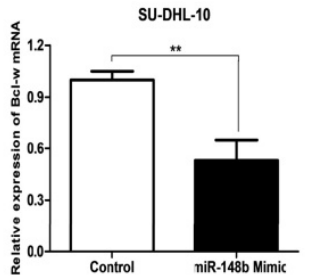

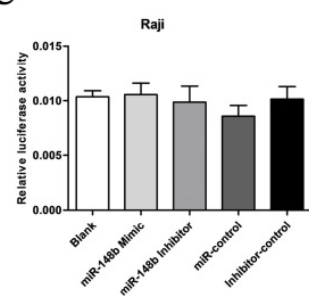

E

C

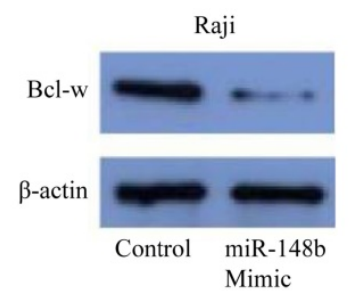

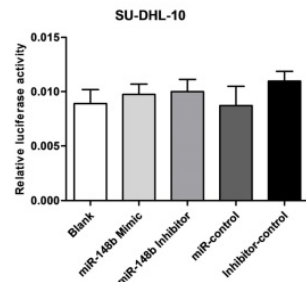

SU-DHL-10

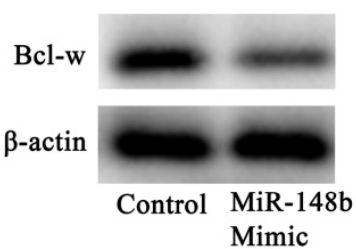

Figure 1. Bcl-w is a direct target of miR-148b in BCL cells. (A) Schematic diagram of the reporter constructs containing the predicted miR-148b binding site in the 3 'UTR of Bcl-w. (B) miR-148b mimic or inhibitor significantly changed the luciferase activity of Bcl-w 3'UTR in Raji and SU-DHL-10 cells co-transfected with wt 3'UTR. (C) miR-148b mimic or inhibitor had no significant effect on the luciferase activity of mut 3'UTR in Raji and SU-DHL-10 cells co-transfected with mut 3'UTR. (D) PCR analysis of Bcl-w mRNA level in Raji cells and SU-DHL-10 cells transfected with control or miR-148b mimic. (E) Representative blots showing Bcl-w protein level in Raji cells and SU-DHL-10 cells transfected with control or miR-148b mimic. $\beta$-actin was loading control. Data were expressed as mean $\pm S D(* P<0.05, * * P<0.01, * * * P<0.001, n=3)$.

\section{A}
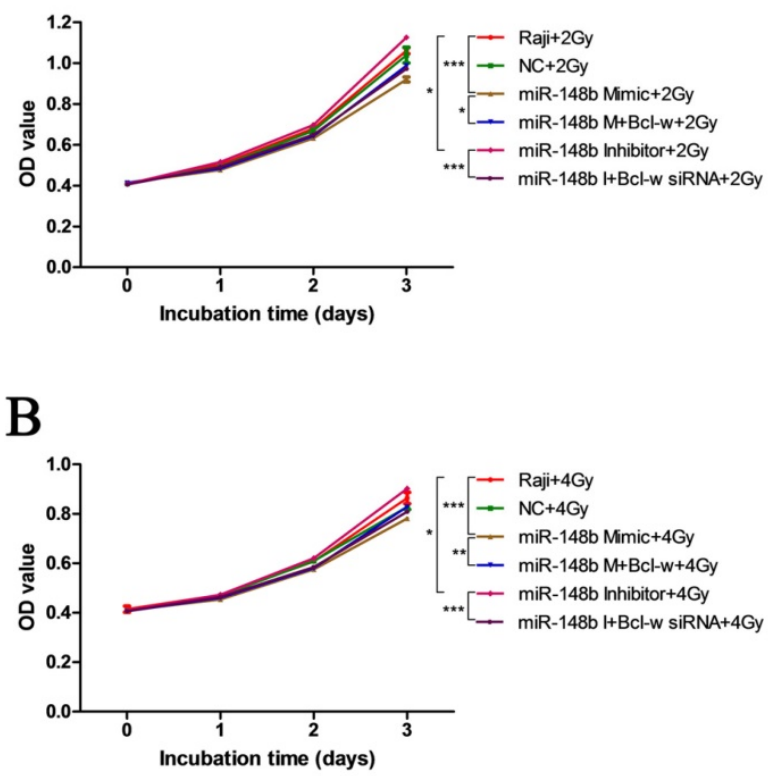
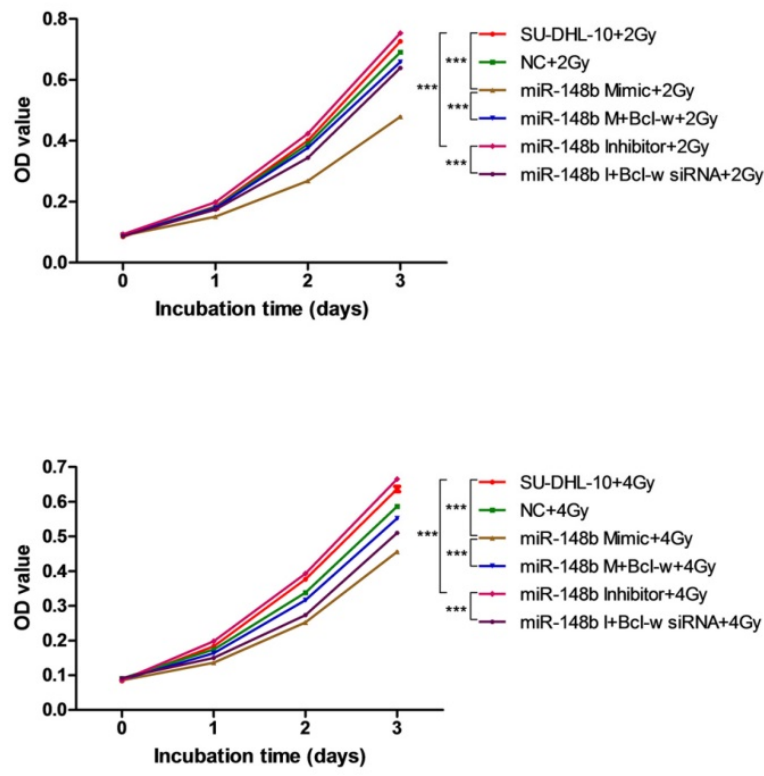

Figure 2. miR-148b targets Bcl-w to reduce the viability of BCL cells after irradiation. Both Raji and SU-DHL-10 cells were divided into two groups and exposed to 2 Gy or 4 Gy radiation. Cells were transfected with the same gene expression modulation reagents. The effect of these reagents on cell viability was similar at both doses. (A) The viability of Raji and SU-DHL-10 cells after being exposed to $2 \mathrm{~Gy}$ and transfected with miR-148b mimic or inhibitor or Bcl-w expression vector or siRNA. (B) The viability of Raji and SU-DHL-10 cells after exposed to $4 \mathrm{~Gy}$ and transfected with miR-148b mimic or inhibitor or Bcl-w expression vector or siRNA. Data were expressed as mean \pm SD $(* \mathrm{P}<0.05$, ** $\mathrm{P}<0.01, * * * \mathrm{P}<0.001, \mathrm{n}=3)$. 
A
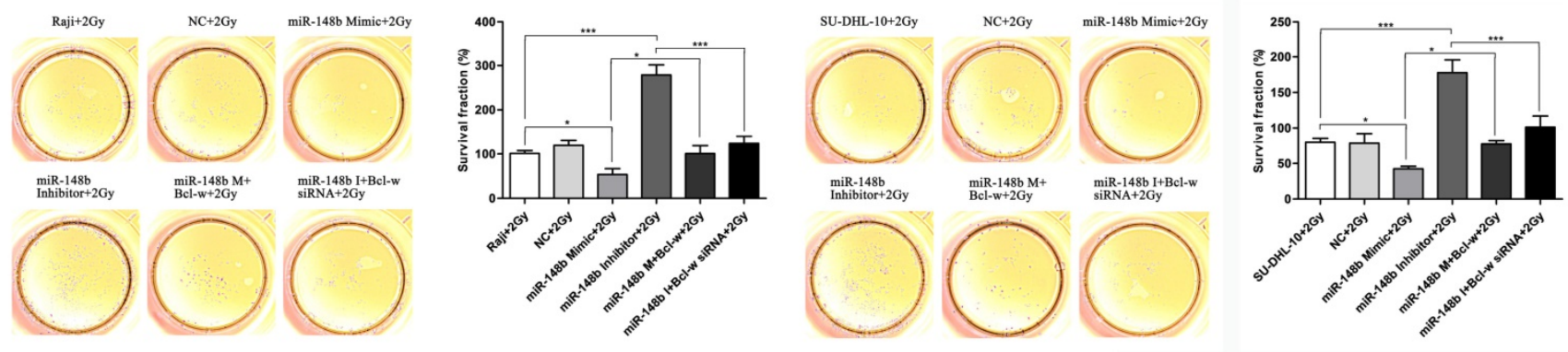

B
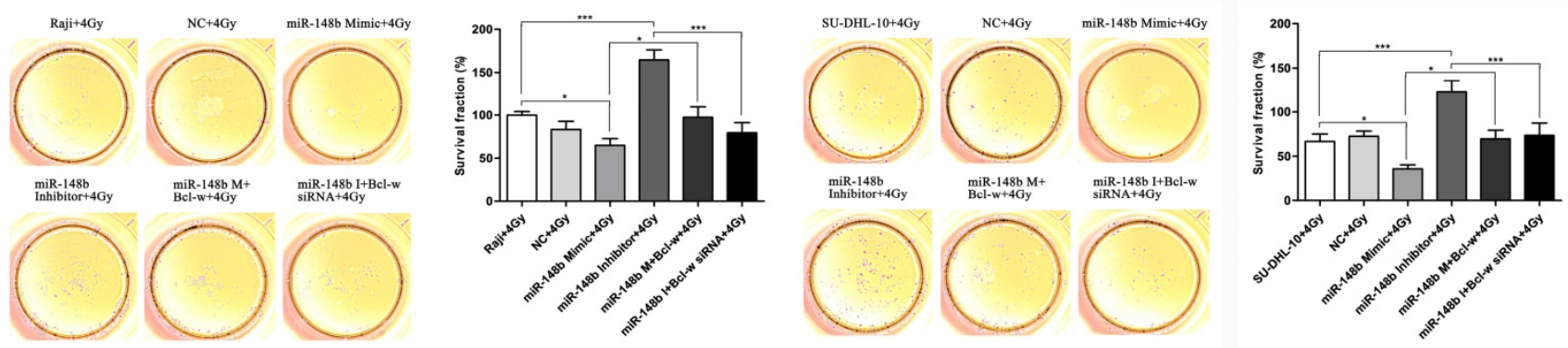

Figure 3. miR-148b targets Bcl-w to inhibit the colony formation of BCL cells after irradiation. Raji and SU-DHL- 10 cells were divided into two groups and exposed to 2 Gy or 4 Gy radiation. Cells were transfected with the same gene expression modulation reagents. The effect of these reagents on cell colony formation was similar, regardless of the dose of radiation administered. (A) The colony formation of Raji cells and SU-DHL-10 cells exposed to $2 \mathrm{~Gy}$ and transfected with miR-148b mimic or inhibitor or Bcl-w expression vector or siRNA. (B) The colony formation of Raji cells and SU-DHL-10 cells exposed to 4Gy and transfected with miR-148b mimic or inhibitor or Bcl-w expression vector or siRNA. Data were expressed as mean $\pm \mathrm{SD}(* \mathrm{P}<0.05$, $* * * \mathrm{P}<0.001, \mathrm{n}=3)$.

A
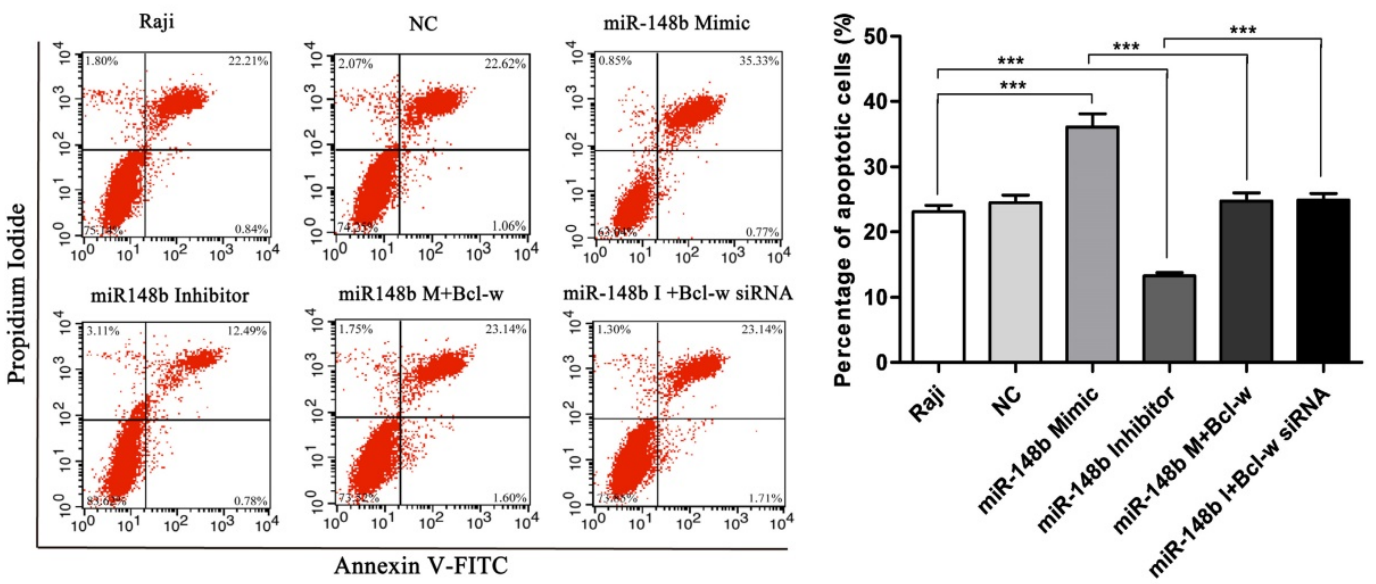

B
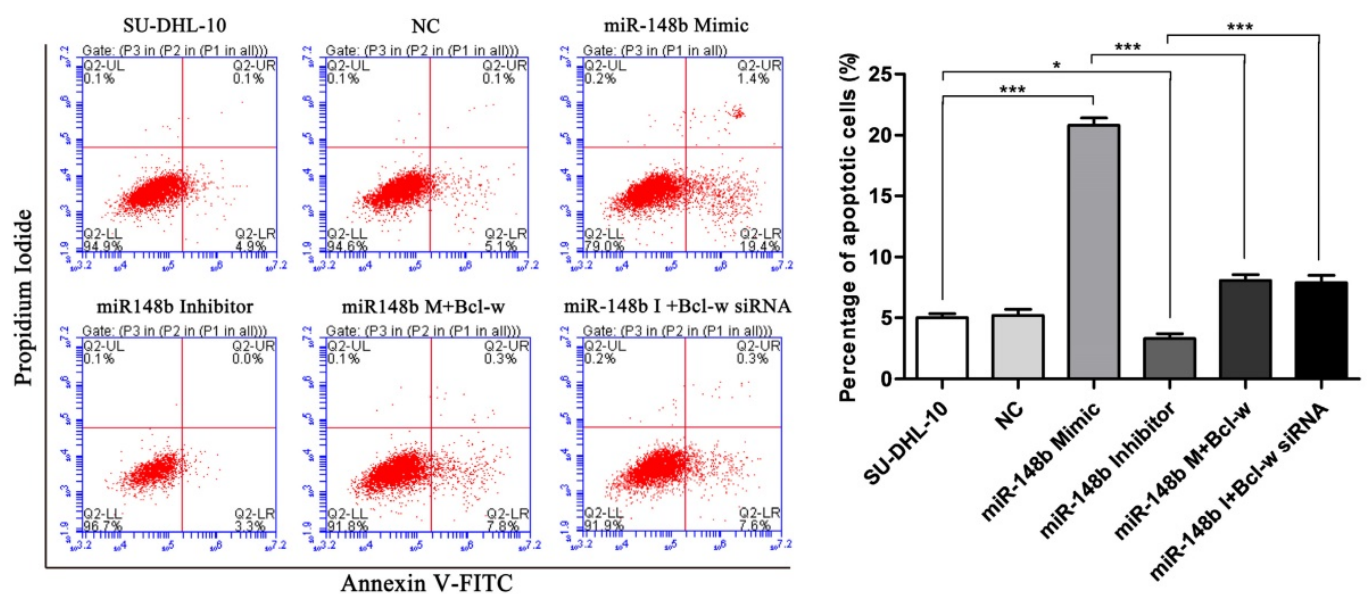

Figure 4. miR-148b targets Bcl-w to promote apoptosis of BCL cells after irradiation. The apoptosis of Raji (A) and SU-DHL-10 (B) cells transfected with miR-148b mimic or inhibitor or $\mathrm{Bcl}-\mathrm{w}$ expression vector or siRNA. Data were expressed as mean $\pm S D(* P<0.05, * * * P<0.001, n=3)$. 
A

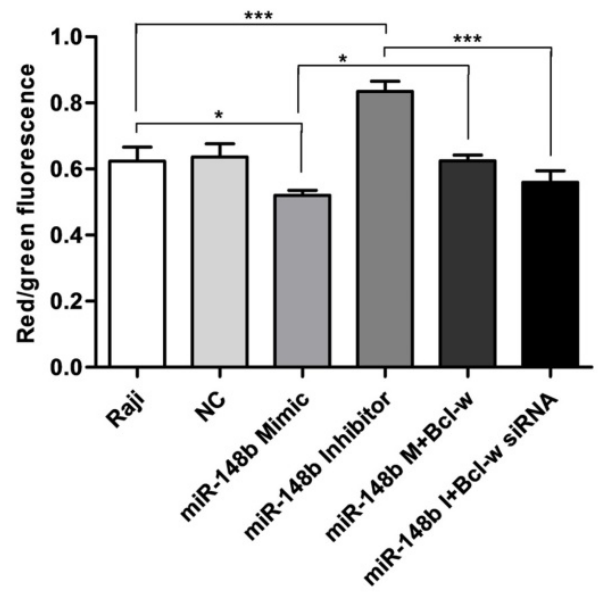

C
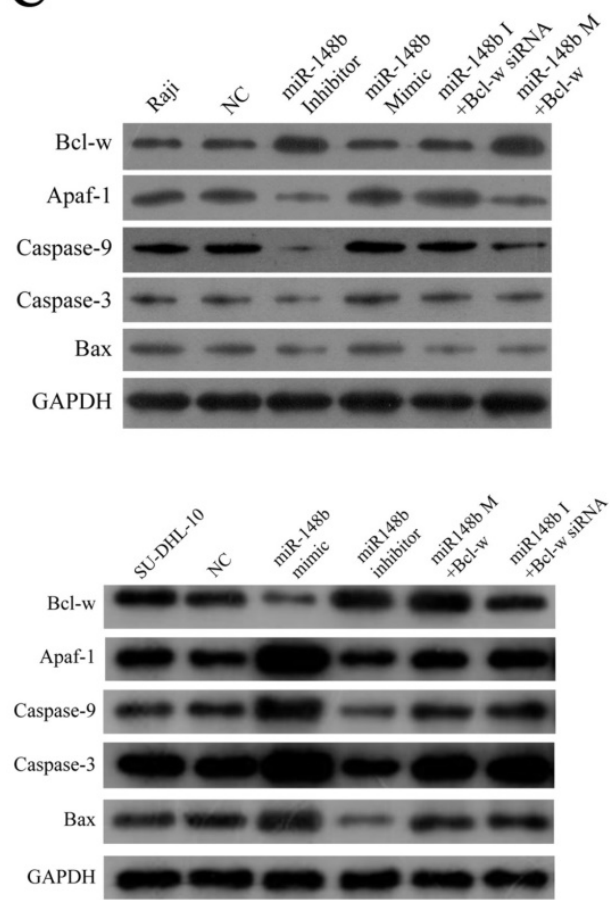

B

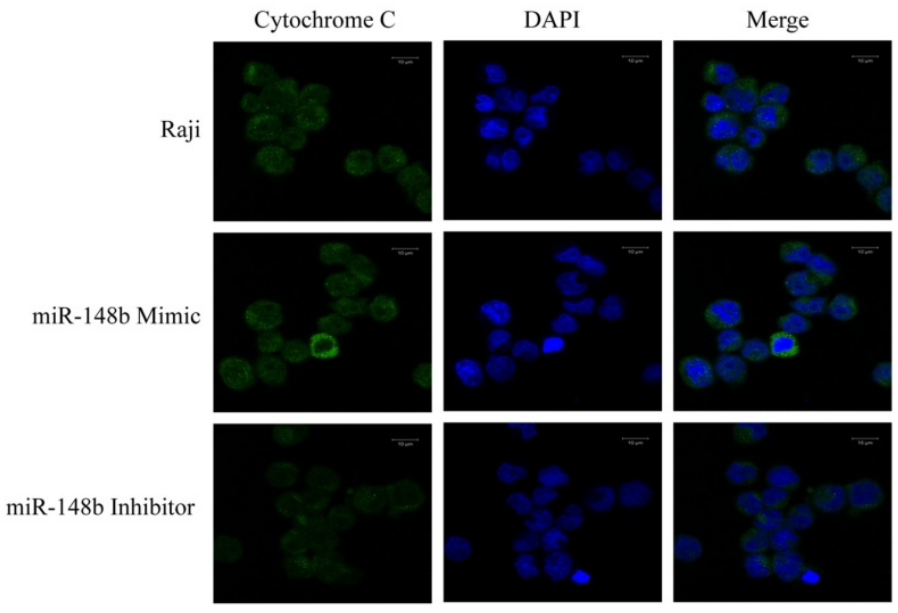

$\square$ Raji

a NC

$\square$ miR-148b Inhibitor

$\square$ miR-148b l+Bcl-w siRNA

$\square$ miR-148b Mimic

$\square$ miR-148b M+Bcl-w

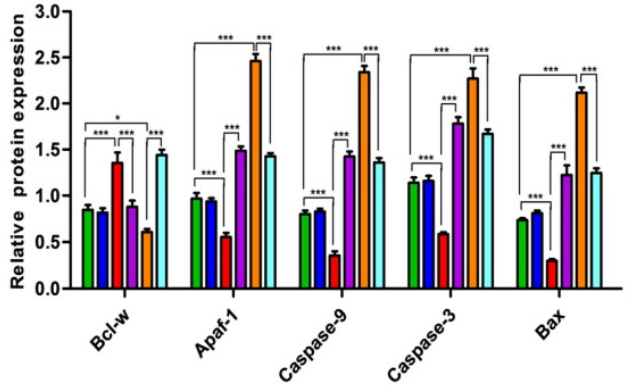

$\square$ SU-DHL-10

- NC

miR-148b Inhibitor

miR-148b l+Bcl-w siRNA

miR-148b Mimic

$\square \mathrm{miR}-148 \mathrm{~b}$ M+Bcl-w

Figure 5. miR-148b targets Bcl-w to reverse the inhibition of mitochondrial apoptotic pathway. (A) The mitochondrial membrane potential of Raji cells transfected with miR-148b mimic or inhibitor or Bcl-w expression vector or siRNA. (B) The release of cytochrome C in Raji cells transfected with miR-148b mimic or inhibitor or Bcl-w expression vector or siRNA. (C) Western blot analysis of the expression of apoptosis related proteins in Raji and SU-DHL-10 cells transfected with miR-148b mimic or inhibitor or $\mathrm{Bcl}-\mathrm{w}$ expression vector or siRNA. The cleaved caspase 9 and caspase 3 were quantified. GAPDH was loading control. Data were expressed as mean $\pm \mathrm{SD}(* \mathrm{P}<0.05, * *$ $\mathrm{P}<0.01$, **** $\mathrm{P}<0.001, \mathrm{n}=3$ ).
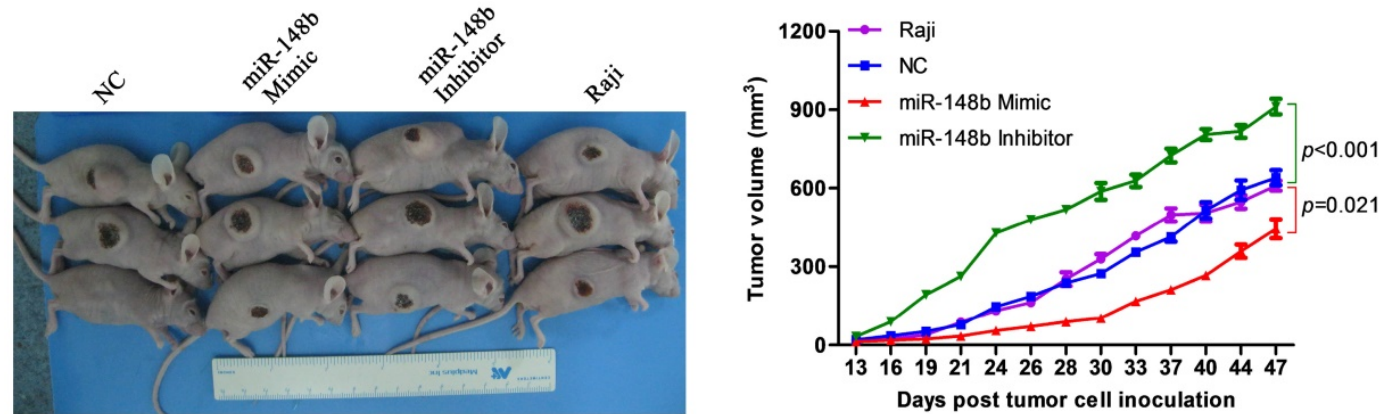

Figure 6. miR-148b inhibits tumor formation in irradiated Raji cells in vivo. Irradiated control Raji cells and irradiated Raji cells transfected with miR-148b mimic or inhibitor were inoculated subcutaneously into nude mice, tumor volume was measured and tumor growth curves were created. 


\section{miR-148b is downregulated and $B c l-w$ is upregulated in BCL patients}

The expression levels of miR-148b were comparatively studied in the peripheral blood samples from 18 healthy volunteers and $21 \mathrm{BCL}$ patients, and in lymph tissue samples from 20 healthy volunteers and $30 \mathrm{BCL}$ patients. It was found that the level of miR-148b in peripheral blood mononuclear cells (MNCs) was significantly lower in BCL patients than in healthy volunteers $(0.893 \pm 0.541$ vs. $1.682 \pm 0.549, p<0.001$, Figure 7A). On the contrary, the level of Bcl-w expression in peripheral blood MNCs was significantly higher in BCL patients than in healthy volunteers $(101.71 \pm 43.922$ vs.7.649 $\pm 6.947, p<$ 0.001 , Figure 7B). The level of miR-148b was significantly negatively correlated with the level of Bcl-w levels in peripheral blood MNCs $(\gamma=-0.821, p<$ 0.0001 , Figure 7C). The level of miR-148b in lymph tissues was significantly lower in BCL patients than in healthy volunteers $(0.647 \pm 0.797$ vs. $2.257 \pm 2.157, p<$ 0.001 , Figure 8B). On the contrary, lymph tissue Bcl-w immunohistochemistry (IHC) scores were

A

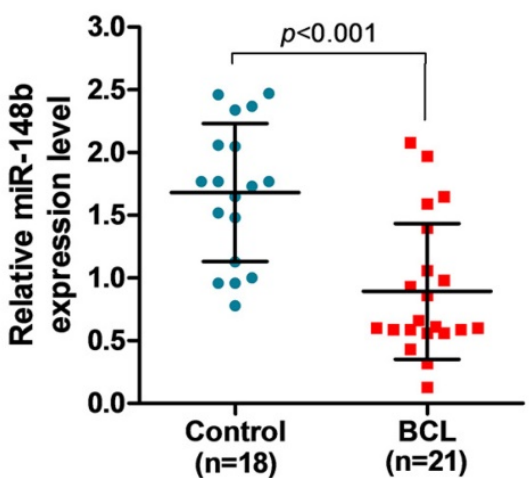

C

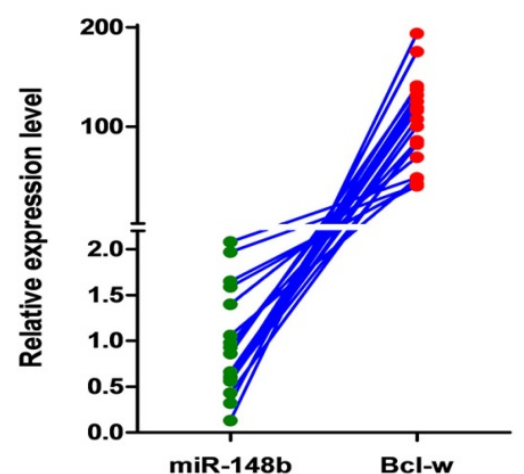

significantly higher in BCL patients than in healthy volunteers $(6.600 \pm 3.024$ vs. $0.350 \pm 0.813, p<0.001$, Figure 8A). There was a significantly negative correlation between the level of miR148b and the Bcl-w IHC scores in lymph tissues $(\gamma-0.651, p<0.0001$, Figure 8C).

\section{Decreased lymph tissue cell apoptosis is associated with the expression of $\mathrm{miR}-148 \mathrm{~b}$ and $\mathrm{BCl}-\mathrm{w}$ in $\mathrm{BCL}$ patients}

The relationship between cell apoptosis and miR-148b was studied in the lymphatic tissues of 20 healthy volunteers and $30 \mathrm{BCL}$ patients by TUNEL assay. The lymphatic tissue apoptosis index was significantly lower in BCL patients than in healthy volunteers $(1.727 \pm 2.440$ vs. $4.570 \pm 3.723, p=0.003$, Figure 9A). The apoptosis index was significantly correlated with the level of miR-148b in the lymphatic tissue of BCL patients $(\gamma=0.5735, p=0.0009$, Figure $9 \mathrm{~B})$. On the contrary, there was a negative correlation between apoptosis index and Bcl-w IHC scores $(\gamma=$ $-0.4028, p=0.0273$, Figure 9C).

B
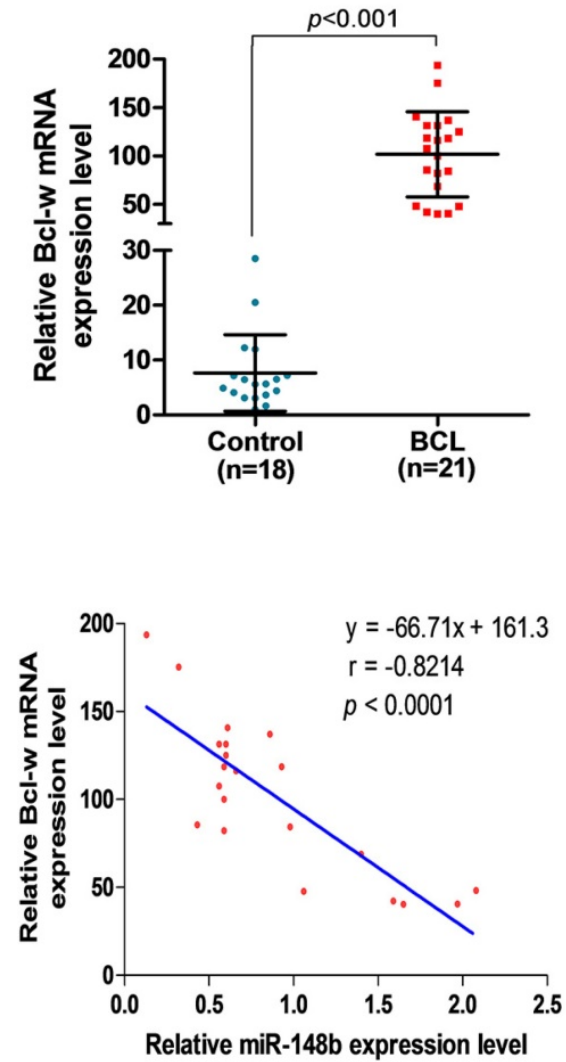

Figure 7. Downregulated miR-148b and upregulated Bcl-w levels in MNCs of BCL patients. (A) The relative expression level of miR-148b in peripheral blood MNCs was significantly lower in BCL patients than in healthy volunteers. (B) The relative expression level of Bcl-w in peripheral blood MNCs was significantly higher in BCL patients than in healthy volunteers. (C) The significant negative correlation between miR-148b and Bcl-w levels in $B C L$ patients $(\gamma=-0.821$, P<0.001). MNC, mononuclear cell. 
A Control

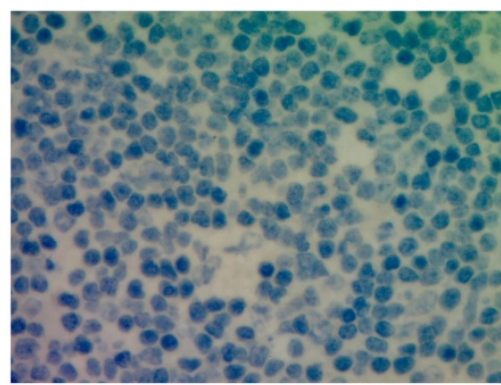

B

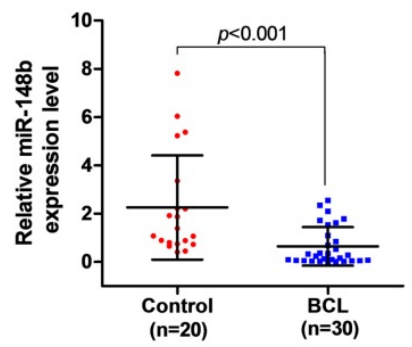

BCL
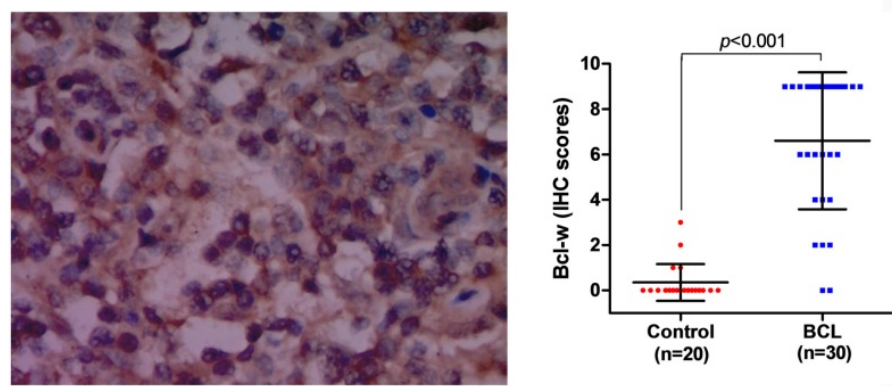

C
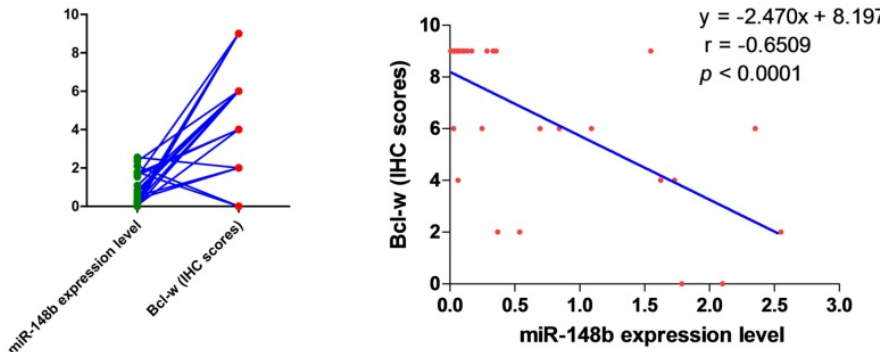

Figure 8. Expression levels of miR-148b and Bcl-w were detected in lymphoid tissues of BCL patients. (A) Assessment of differences in $B c l-w$ expression levels between $B C L$ patients and normal lymphoid tissues by immunohistochemistry. (B) Detection of miR-148b expression levels in BCL patients and normal lymphoid tissues by qPCR. (C) The significant negative correlation between miR-148b and Bcl-w levels in lymphoid tissue of BCL patients $(\gamma=-0.6509, P<0.001)$.

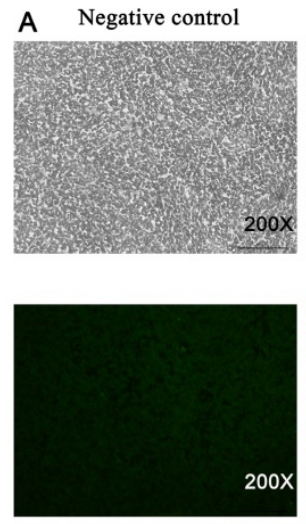

B

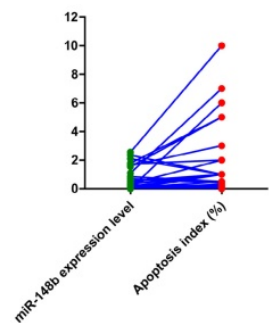

Positive control
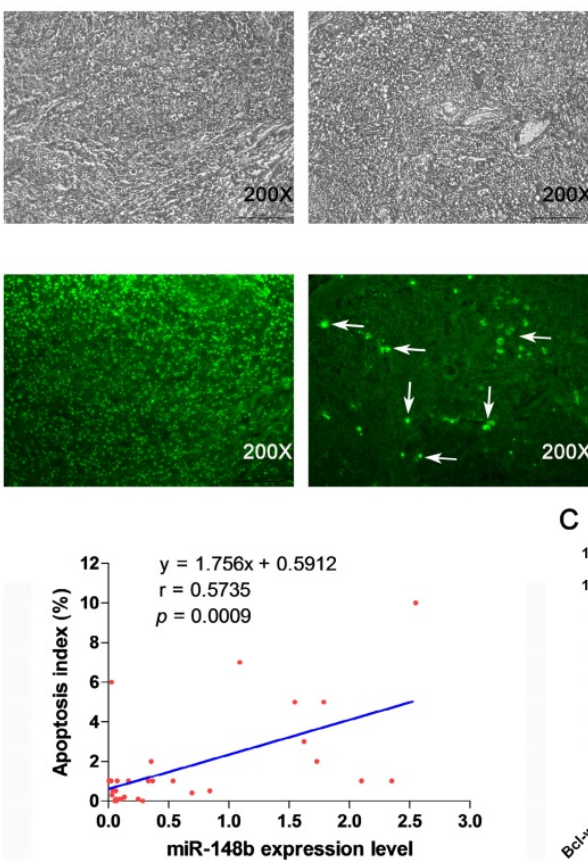

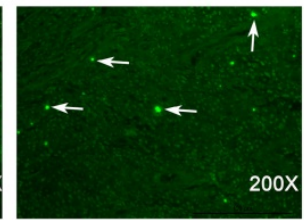

C

$\mathrm{BCL}$
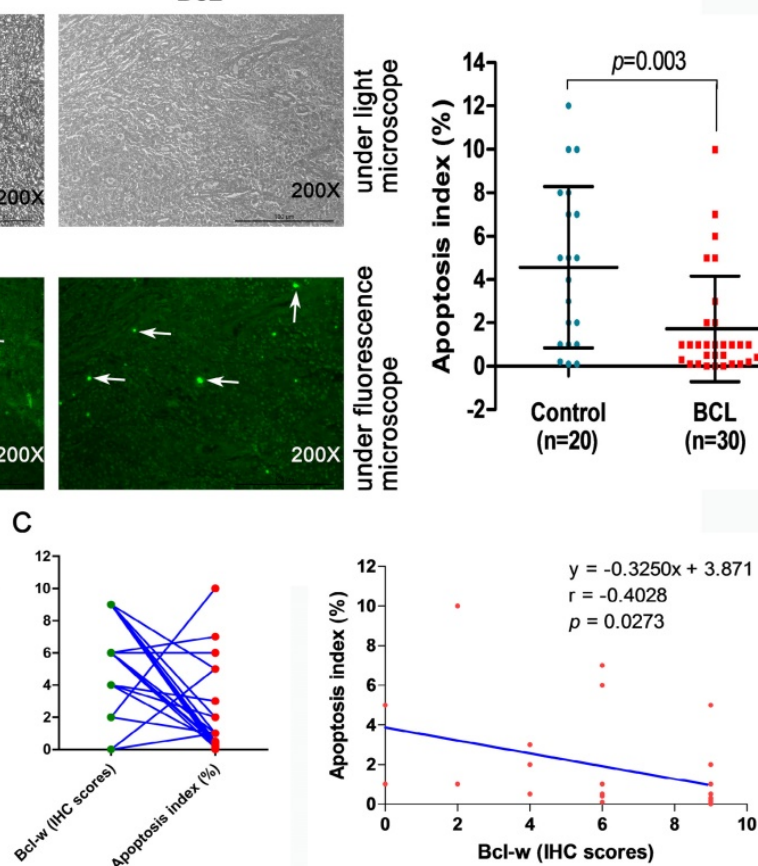

Figure 9. Correlation between expression levels of miR-148b and Bcl-w and apoptosis in lymphoid tissues of patients with BCL. (A) Detection of apoptosis in BCL patients and normal lymphoid tissues by TUNEL assay. (B) Relationship between expression level of miR-148b and apoptosis in lymphoid tissues. (C) Relationship between IHC score of Bcl-w and apoptosis in lymphoid tissues. IHC, immunohistochemistry.

\section{Discussion}

In this study, it was found that miR-148b targeted Bcl-w in BCL cells, influenced the number of viable cells and colony formation through targeting $\mathrm{Bcl}-\mathrm{w}$ and reversed Bcl-w-mediated inhibition of mitochondrial apoptosis in irradiated BCL cells, and inhibited the growth of the tumors generated from the xenograft BCL cells in mice. In BCL patients, miR-148b was downregulated and $\mathrm{Bcl}-\mathrm{w}$ is upregulated in BCL patients; miR-148b was negatively correlated with Bcl-w in both peripheral blood MNCs and lymph tissues; cell apoptosis was decreased in the lymph tissues, which was associated 
with the expression of miR-148b and Bcl-w. These results demonstrated that miR-148b increased the radiosensitivity of B-cell lymphoma cells by targeting $\mathrm{Bcl}-\mathrm{w}$ to promote apoptosis.

The dual-luciferase reporter assay indicated that miRNA-148b directly targeted the 3'UTR of Bcl-w and suppressed the expression of Bcl-w mRNA and protein in cultured BCL cells, which confirms the proposal in a previous study that Bcl-w may be a target of miRNA-148b [35]. The downregulation of miR-148b, upregulation of $\mathrm{Bcl}-\mathrm{w}$ and the negative correlation between miR-148b level and Bcl-w level in the peripheral blood and lymph tissues of $\mathrm{BCL}$ patients suggest that miR-148b suppresses the expression of Bcl-w in vivo.

Our study showed that miR-148b mimics decreased cell viability and inhibited colony formation while miR-148b inhibitor promoted cell viability and colony formation in irradiated BCL cells. These effects of miR-148b on cell viability and colony formation were reversed by overexpression or knockdown of Bcl-w. In irradiated BCL cell xenograft mice miR-148b inhibited the tumor growth while miR-148b inhibitor promoted the tumor growth. These results suggest that miR- $148 \mathrm{~b}$ targets $\mathrm{Bcl}-\mathrm{w}$ to decrease the number of viable cells so as to inhibit the tumor growth. miR-148b mimic triggered an increase in mitochondrial mediated apoptosis while miR-148b inhibitor decreased mitochondrial mediated apoptosis in BCL cells, suggesting that miR-148b promotes mitochondrial mediated apoptosis in BCL cells, which is in agreement with our previous observation [33]. The reversion of miR-148b mimic and inhibitor mediated effects on mitochondrial mediated apoptosis by intervention of Bcl-w expression indicated that miR-148b increased mitochondrial mediated apoptosis through targeting Bcl-w, which led to the decrease in the number of viable cells and reduction in tumor growth in irradiated BCL cells.

It was found that in BCL patients, miR-148b was downregulated and $\mathrm{Bcl}-\mathrm{w}$ is upregulated; miR-148b was negatively correlated with Bcl-w in both peripheral blood MNCs and lymph tissues; cell apoptosis was decreased in the lymph tissues; cell apoptosis index was positively correlated with the expression of miR-148b and negatively correlated with Bcl-w. Based on the observation in this study that miR-148b directly targeted Bcl-w, it is obvious that miR-148b increases apoptosis by suppressing $\mathrm{Bcl}-\mathrm{w}$ in BCL patients.

Apoptosis is essential for maintaining tissue balance and cellular integrity [39]. Malignant tumors may develop when apoptosis-related genetic mutations or abnormal expression block apoptosis; tumor treatment may induce apoptosis-related gene expression to promote tumor cell apoptosis [40-44]. Previously we found that miR-148b, which promotes radiation-induced apoptosis, enhanced the radiosensitivity of BCL cells [33]. In this study, it was found that miR-148b inhibited tumor growth by targeting Bcl-w and promoting apoptosis in irradiated BCL cells, and promoted apoptosis by suppressing $\mathrm{Bcl}-\mathrm{w}$ in BCL patients. These observations indicate that miR-148b increases radiosensitivity of BCL cells by targeting Bcl-w to increase apoptosis.

\section{Conclusion}

In conclusion, miR-148b directly targets Bcl-w and regulates the expression of Bcl-w in BCL patients and cultured BCL cells. miR-148b increased the apoptosis in BCL patients, decreased the number of viable cells, colony formation and tumor growth through increasing apoptosis in irradiated BCL cells. miR-148b promotes radiosensitivity by targeting $\mathrm{Bcl}-\mathrm{w}$ to activate mitochondrial mediated apoptosis in BCL cells.

\section{Abbreviations}

miR-148b: MicroRNA-148b; Bcl-w: B cell lymphoma-w; BCL: B-cell lymphoma; MNC: mononuclear cell; wt 3'-UTR: wild-type 3'-Untranslated region; mut 3'-UTR: mutated 3'-Untranslated region; GFP: Green fluorescent protein; siRNA: small interfering RNA; qRT-PCR: Real-time quantitative polymerase chain reaction; IHC: Immunohistochemistry; TUNEL: Terminal deoxynucleotidyl transferase-mediated dUTP nick-end labeling; CCK-8: Cell Counting Kit-8; MMP: Mitochondrial membrane potential; Annexin V/PI: Annexin V / propidium iodide.

\section{Acknowledgements}

\section{Funding}

The present study was supported by the National Nature Science Foundation of China (Grant No. 31971164, 81201864, 31601031, 81672900), Fundamental Research Funds for the Central Universities (Grant No. 2018MS20), the Guangdong Special Fund Project of Fundamental and Applied Research (Grant No. 2018A030313160, 2016A030310109), and the Guangzhou Planned Project of Science and Technology (Grant No. 201804010221, 201707010262).

\section{Ethics Committee Approval and Patient Consent}

All subjects gave their informed consent for inclusion before they participated in the study. The 
study was conducted in accordance with the Declaration of Helsinki, and the protocol was approved by the Ethics Committee of Guangzhou First People's Hospital (Project identification code: K-2017-133-01).

\section{Author Contributions}

S.H.L. and P.P.W. performed the research and wrote the manuscript. C.T.C., D.L., Q.Y.L., L.L., X.L., L.N.W., B.X.L., C.Y.W., and X.S.F. collected and analyzed the data. X.J.C., S.L.L., and S.X.Z. analyzed the data. G.L.L. and Y.W. designed the project. All authors have read and approved the final manuscript.

\section{Competing Interests}

The authors have declared that no competing interest exists.

\section{References}

1. Ansell SM, Arendt BK, Grote DM, Jelinek DF, Novak AJ, Wellik LE, et al. Inhibition of survivin expression suppresses the growth of aggressive non-Hodgkin's lymphoma. Leukemia. 2004; 18: 616-23.

2. Wu H, Ma Y, Zhu Y, Shen Y, Gu C, Ye Z, et al. Expression of BIRC7 protein and mRNA in non-Hodgkin's lymphoma. Leuk Lymphoma. 2006; 47: 1110-6.

3. Fernandez-Marrero Y, Spinner S, Kaufmann T, Jost PJ. Survival control of malignant lymphocytes by anti-apoptotic MCL-1. Leukemia. 2016; 30: 2152-9.

4. Song W, Liu MG, Zhang JB, Zhang JJ, Sun MM, Yu OK. Mechanism of action of EBV, Bcl-2, p53, c-Myc and Rb in non-Hodgkin's lymphoma. Eur Rev Med Pharmacol Sci. 2016; 20: 1093-7.

5. Kang $\mathrm{MH}$, Reynolds $\mathrm{CP}$. Bcl-2 inhibitors: targeting mitochondrial apoptotic pathways in cancer therapy. Clin Cancer Res. 2009; 15: 1126-32.

6. Merino D, Lok SW, Visvader JE, Lindeman GJ. Targeting BCL-2 to enhance vulnerability to therapy in estrogen receptor-positive breast cancer. Oncogene. 2016; 35: 1877-87.

7. Lee EF, Harris TJ, Tran S, Evangelista M, Arulananda S, John T, et al. BCL-XL and MCL-1 are the key BCL-2 family proteins in melanoma cell survival. Cell Death Dis. 2019; 10: 342.

8. de Jong Y, Monderer D, Brandinelli E, Monchanin M, van den Akker BE, van Oosterwijk JG, et al. Bcl-xl as the most promising Bcl-2 family member in targeted treatment of chondrosarcoma. Oncogenesis. 2018; 7: 74.

9. Kim EM, Kim J, Park JK, Hwang SG, Kim WJ, Lee WJ, et al. Bcl-w promotes cell invasion by blocking the invasion-suppressing action of Bax. Cell Signal. 2012; 24 : 1163-72.

10. Gibson L, Holmgreen SP, Huang DC, Bernard O, Copeland NG, Jenkins NA, et al. bcl-w, a novel member of the bcl-2 family, promotes cell survival. Oncogene. 1996; 13: 665-75.

11. Martinou JC, Youle RJ. Mitochondria in apoptosis: Bcl-2 family members and mitochondrial dynamics. Dev Cell. 2011; 21: 92-101.

12. Eriksson D, Stigbrand T. Radiation-induced cell death mechanisms. Tumour Biol. 2010; 31: 363-72

13. Adams CM, Kim AS, Mitra R, Choi JK, Gong JZ, Eischen CM. BCL-W has a fundamental role in B cell survival and lymphomagenesis. J Clin Invest. 2017; 127: 635-50.

14. Chauhan D, Velankar M, Brahmandam M, Hideshima T, Podar K, Richardson $\mathrm{P}$, et al. A novel Bcl-2/Bcl-X(L)/Bcl-w inhibitor ABT-737 as therapy in multiple myeloma. Oncogene. 2007; 26: 2374-80.

15. Wang K, Chen X, Zhan Y, Jiang W, Liu X, Wang X, et al. miR-335 inhibits the proliferation and invasion of clear cell renal cell carcinoma cells through direct suppression of BCL-W. Tumour Biol. 2015; 36: 6875-82.

16. Fang L, Li Z, Chen YJ, Xiao GM. Cyramza induces apoptosis of HCC4006 cell by affecting the level of Bcl-w. Eur Rev Med Pharmacol Sci. 2017; 21: 3069-74.

17. Carrington JC, Ambros V. Role of microRNAs in plant and animal development. Science. 2003; 301: 336-8.

18. Wang P, Zhang J, Zhang L, Zhu Z, Fan J, Chen L, et al. MicroRNA 23b regulates autophagy associated with radioresistance of pancreatic cancer cells. Gastroenterology. 2013; 145: 1133-43.e12.

19. Weidhaas JB, Babar I, Nallur SM, Trang P, Roush S, Boehm M, et al, MicroRNAs as potential agents to alter resistance to cytotoxic anticancer therapy. Cancer Res. 2007; 67: 11111-6.

20. Ke G, Liang L, Yang JM, Huang X, Han D, Huang S, et al. MiR-181a confers resistance of cervical cancer to radiation therapy through targeting the pro-apoptotic PRKCD gene. Oncogene. 2013; 32: 3019-27.

21. Zhang P, Wang L, Rodriguez-Aguayo C, Yuan Y, Debeb BG, Chen D, et al. miR-205 acts as a tumour radiosensitizer by targeting ZEB1 and Ubc13. Nat Commun. 2014; 5: 5671.
22. de Jong MC, Ten Hoeve JJ, Grenman R, Wessels LF, Kerkhoven R, Te Riele H, et al. Pretreatment microRNA Expression Impacting on Epithelial-to-Mesenchymal Transition Predicts Intrinsic Radiosensitivity in Head and Neck Cancer Cell Lines and Patients. Clin Cancer Res. 2015; 21: 5630-8.

23. Hao C, Xu X, Ma J, Xia J, Dai B, Liu L, et al. MicroRNA-124 regulates the radiosensitivity of non-small cell lung cancer cells by targeting TXNRD1. Oncol Lett. 2017; 13: 2071-8.

24. Mao A, Zhao Q, Zhou X, Sun C, Si J, Zhou R, et al. MicroRNA-449a enhances radiosensitivity by downregulation of c-Myc in prostate cancer cells. Sci Rep. 2016; 6: 27346

25. Nelson P, Kiriakidou M, Sharma A, Maniataki E, Mourelatos Z. The microRNA world: small is mighty. Trends Biochem Sci. 2003; 28: 534-40.

26. Shin S, Cha HJ, Lee EM, Jung JH, Lee SJ, Park IC, et al. MicroRNAs are significantly influenced by p53 and radiation in HCT116 human colon carcinoma cells. Int J Oncol. 2009; 34: 1645-52.

27. Czochor JR, Glazer PM. microRNAs in cancer cell response to ionizing radiation. Antioxid Redox Signal. 2014; 21: 293-312.

28. Liu GL, Liu X, Lv XB, Wang XP, Fang XS, Sang Y. miR-148b functions as a tumor suppressor in non-small cell lung cancer by targeting carcinoembryonic antigen (CEA). Int J Clin Exp Med. 2014; 7: 1990-9.

29. Mou Z, Xu X, Dong M, Xu J. MicroRNA-148b Acts as a Tumor Suppressor in Cervical Cancer by Inducing G1/S-Phase Cell Cycle Arrest and Apoptosis in a Caspase-3-Dependent Manner. Med Sci Monit. 2016; 22: 2809-15.

30. Song YX, Yue ZY, Wang ZN, Xu YY, Luo Y, Xu HM, et al. MicroRNA-148b is frequently down-regulated in gastric cancer and acts as a tumor suppressor by inhibiting cell proliferation. Mol Cancer. 2011; 10: 1

31. Cimino D, De Pitta C, Orso F, Zampini M, Casara S, Penna E, et al. miR148b is a major coordinator of breast cancer progression in a relapse-associated microRNA signature by targeting ITGA5, ROCK1, PIK3CA, NRAS, and CSF1. Faseb j. 2013; 27: 1223-35.

32. Song $\mathrm{Y}, \mathrm{Xu} \mathrm{Y}$, Wang Z, Chen Y, Yue Z, Gao P, et al. MicroRNA-148b suppresses cell growth by targeting cholecystokinin-2 receptor in colorectal cancer. Int J Cancer. 2012; 131: 1042-51.

33. Wu $Y$, Liu GL, Liu SH, Wang $C X, X u$ YL, Ying $Y$, et al. MicroRNA-148b enhances the radiosensitivity of non-Hodgkin's Lymphoma cells by promoting radiation-induced apoptosis. J Radiat Res. 2012; 53: 516-25.

34. Zhang $\mathrm{H}, \mathrm{Li} Y$, Huang $\mathrm{O}$, Ren $\mathrm{X}, \mathrm{Hu} \mathrm{H}$, Sheng $\mathrm{H}$, et al. MiR-148a promotes apoptosis by targeting Bcl-2 in colorectal cancer. Cell Death Differ. 2011; 18: 1702-10

35. Danial NN. BCL-2 family proteins: critical checkpoints of apoptotic cell death. Clin Cancer Res. 2007; 13: 7254-63.

36. Pritchard DM, Print C, O'Reilly L, Adams JM, Potten CS, Hickman JA. Bcl-w is an important determinant of damage-induced apoptosis in epithelia of small and large intestine. Oncogene. 2000; 19: 3955-9.

37. Kammerer U, Kapp M, Gassel AM, Richter T, Tank C, Dietl J, et al. A new rapid immunohistochemical staining technique using the EnVision antibody complex. J Histochem Cytochem. 2001; 49: 623-30.

38. Li DY, Shi XJ, Li W, Sun XD, Wang GY. Ischemic preconditioning and remote ischemic preconditioning provide combined protective effect against ischemia/reperfusion injury. Life Sci. 2016; 150: 76-80.

39. Cotter TG. Apoptosis and cancer: the genesis of a research field. Nat Rev Cancer. 2009; 9: 501-7.

40. Croce CM, Reed JC. Finally, An Apoptosis-Targeting Therapeutic for Cancer. Cancer Res. 2016; 76: 5914-20.

41. Dive C, Evans CA, Whetton AD. Induction of apoptosis--new targets for cancer chemotherapy. Semin Cancer Biol. 1992; 3: 417-27.

42. Chang L, Graham PH, Hao J, Ni J, Bucci J, Cozzi PJ, et al. PI3K/Akt/mTOR pathway inhibitors enhance radiosensitivity in radioresistant prostate cancer cells through inducing apoptosis, reducing autophagy, suppressing NHEJ and HR repair pathways. Cell Death Dis. 2014; 5: e1437.

43. Muschel RJ, Soto DE, McKenna WG, Bernhard EJ. Radiosensitization and apoptosis. Oncogene. 1998; 17: 3359-63.

44. Lewanski CR, Gullick WJ. Radiotherapy and cellular signalling. Lancet Oncol. $2001 ; 2: 366-70$ 